8. Széll Z, Bacsadi Á, Szeredi L, Nemes C, Fézer B, Bakcsa E, et al. Rapid spread and emergence of heartworm resulting from climate and climate-driven ecological changes in Hungary. Vet Parasitol. 2020;280:109067. https:/ / doi.org/ 10.1016/j.vetpar.2020.109067

9. Miterpáková M, Hurníková Z, Valentová D, Borková L. Different epidemiological pattern of canine dirofilariosis in two neighboring countries in Central Europe-the Czech Republic and Slovakia. Parasitol Res. 2021;120:547-52. https:/ / doi.org/10.1007/s00436-020-06995-8

10. Seybold WD. Solitary or "coin" lesions of the lung. Postgrad Med. 1964;36:424-30. https:/ / doi.org/10.1080/00325481.196 4.11695320

Address for correspondence: Daniela Antolová, Institute of Parasitology SAS, Hlinkova 3, 04001 Košice, Slovakia; email: antolova@saske.sk

\section{Fatal Case of Mediterranean Spotted Fever Associated with Septic Shock, Iran}

\author{
Saber Esmaeili, Mina Latifian, Mohammad Khalili, \\ Mehrdad Farrokhnia, John Stenos, Mehdi Shafiei, \\ Ehsan Mostafavi \\ Author affiliations: Pasteur Institute of Iran, Tehran, Iran \\ (S. Esmaeili, M. Latifian, E. Mostafavi); Pasteur Institute of Iran, \\ Akanlu, Iran (S. Esmaeili, M. Latifian, E. Mostafavi); Shahid \\ Bahonar University of Kerman, Kerman, Iran (M. Khalili); \\ Kerman University of Medical Sciences, Kerman (M. Farrokhni, \\ M. Shafiei); University Hospital Geelong, Geelong, Victoria, \\ Australia (J. Stenos)
}

\begin{abstract}
A fatal case of Mediterranean spotted fever associated with septic shock was reported in a 61-year-old man living in a village in southeastern Iran. The patient had a history of tick bite a few days before symptom onset. Phylogenetic analysis confirmed infection by Rickettsia conorii subspecies israelensis.
\end{abstract}

DOI: https://doi.org/10.3201/eid2802.211023

$\mathrm{M}$ editerranean spotted fever (MSF) is a zoonotic disease caused by Rickettsia conorii. The main vector of this bacterium is the Rhipicephalus sanguineus tick (1); the main hosts of these ticks are domestic dogs, and humans are incidental hosts (2). MSF is endemic to the Mediterranean, Europe, Africa, western Asia, and India. The case-fatality rate is $3 \%-7 \%$ in hospitalized patients $(3,4)$.

In 2017, human cases of MSF were reported in Kerman province in southeastern Iran (5). No data are available on the epidemiology of MSF in Iran; we report a fatal case of MSF associated with septic shock.

The patient was a 61-year-old man with a 10year history of hypertension and rheumatoid arthritis who lived in a village in proximity to Bam County, Kerman province, Iran. He was a farmer, had no history of domestic animal-keeping, and reported contact with livestock and a tick bite a few days before symptom onset. The initial clinical signs of the disease appeared on September 6, 2019, and the patient was admitted to a hospital in Bam on September 9; symptoms were fever, nausea, vomiting, myalgia, urinary retention, and flank pain. The patient had scleral icterus, and a black skin eschar at the tick bite site and skin rash were visible on his left leg.

When the patient's condition deteriorated, he was transferred to a hospital in Kerman on September 15. At admission, symptoms were septic shock, tachycardia, tachypnea, fever, and hypotension $(85 / 50 \mathrm{~mm} \mathrm{Hg})$; he immediately began treatment with ceftriaxone, metronidazole, and parenteral hydration. Maculopapular skin rash was visible on the left leg. The patient had thrombocytopenia, and an increase was observed in leukocyte counts, renal factor levels (urea and creatinine), liver enzyme levels (aspartate aminotransferase, alanine transferase, and alkaline phosphatase), partial thromboplastin time of coagulation, and bilirubin levels (Table). Hemoglobin and hematocrit levels decreased, and the patient experienced hematuria and proteinuria; calcium oxalate and amorphous urate crystals were further reported in microscopic examinations. Treatment of prednisolone, heparin, doxycycline, and vancomycin was initiated.

On September 16, the patient was transferred to Afzalipour Hospital in Kerman (Referral Center for Infectious Diseases, Kerman Province). At the time of admission, the patient was conscious, his condition was stable, and his temperature was $37.6^{\circ} \mathrm{C}$. No abnormalities were observed in clinical examinations of the heart, chest, and abdomen, but we noted bilateral lower extremity edema and left leg skin lesions (rash and eschar). The results of laboratory tests of blood and urine samples were 
Table. Laboratory findings in a patient with Mediterranean spotted fever associated with septic shock, Iran*

\begin{tabular}{|c|c|c|c|}
\hline Value & 2019 Sep 16, 12 AM & 2019 Sep 17, 1 AM & 2019 Sep 17, 1 AM \\
\hline Leukocyte, $\times 10^{9} / \mathrm{L}$ & 18,900 & 12,700 & ND \\
\hline Hemoglobin, g/dL & 12.9 & 14.1 & ND \\
\hline Platelets, $\times 10^{9} / \mathrm{L}$ & 56,000 & 42,000 & ND \\
\hline Hematocrit, \% & 35.3 & 43.0 & ND \\
\hline Prothrombin time, $\mathrm{s}$ & 14.4 & 13.5 & 14 \\
\hline Partial thromboplastin time, $\mathrm{s}$ & 56 & 39 & 33 \\
\hline Aspartate aminotransferase, U/L & 83 & 101 & ND \\
\hline Alanine aminotransferase, U/L & 71 & 49 & ND \\
\hline Alkaline phosphatase, U/L & 328 & 510 & ND \\
\hline Bilirubin total, $\mathrm{mg} / \mathrm{dL}$ & 2.7 & 4.8 & ND \\
\hline Bilirubin direct, mg/dL & 2.3 & 2.8 & ND \\
\hline Blood urea, mg/dL & 95 & 145 & 161 \\
\hline Blood creatinine, $\mathrm{mg} / \mathrm{dL}$ & 3.6 & 4.8 & 5.5 \\
\hline Blood calcium, mEq/L & 8.5 & ND & ND \\
\hline Blood sodium, mEq/L & 140 & 135 & 136 \\
\hline Blood potassium, mEq/L & 4.0 & 4.9 & 3.5 \\
\hline Proteinuria & + & - & + \\
\hline Hematuria & + & - & + \\
\hline
\end{tabular}

abnormal (Table). The patient underwent emergency dialysis and continued to take prednisolone, heparin, doxycycline, and vancomycin. On September 17, the patient lost consciousness; he was subsequently intubated and admitted to the intensive care unit. A few hours later, he experienced septic shock and cardiac arrest and died.

The differential diagnosis for this patient included MSF and Crimean-Congo hemorrhagic fever; on September 17, samples required for these differential diagnoses were prepared. Serum and blood samples were sent to the Pasteur Institute of Iran on September 25 (8 days after the patient's death). Serologic and molecular test results for Crimean-Congo hemorrhagic fever were negative. Testing for $R$. conorii IgM by ELISA was borderline, and titer of $R$. conorii $\operatorname{IgM}$ by immunofluorescence assay was 1:48. Serum samples were positive for Rickettsia spp. (16S rRNA gene) by real-time reverse transcription PCR (6). On the basis of the amplification and sequencing of specific genes of Rickettsia spp. (gltA, GenBank accession no. MZ545594.1; 17KD, GenBank accession no. MZ545592.1; ompA, GenBank accession no. MZ545593.1), we confirmed infection by $R$. conorii subspecies israelensis (Figure).

The patient died as a result of late diagnosis of a rickettsial infection and subsequent septic shock, despite initiation of appropriate treatment. MSF is usually considered to be a mild disease, but severe and fatal cases do occasionally occur (7). One of the causes of death from MSF is multiorgan failure, including acute kidney injury, pneumonitis, and encephalitis. When severe, MSF can manifest as septic shock, and acute kidney injury might occur. Thrombocytopenia and elevated liver enzymes are frequent laboratory abnormalities $(4,7)$.

Phylogenetic trees showed that the infection in this patient was caused by $R$. conorii subsp. israelensis. $R$. conorii has 4 subspecies, caspia, israelensis, conorii, and indica, each of which cause diseases that have specific clinical features and occur in different geographic regions. $R$. conorii subsp. israelensis seems to have the highest death rate of the subspecies $(8,9)$, reported to be $\approx 30 \%$ (10).

MSF appears to be circulating in southern Iran but is a neglected disease that requires more attention from the healthcare system. Because of the nonspecific clinical symptoms of MSF, diagnosing the disease is challenging. Diagnosing and treating MSF early is critical to prevent progression to more severe illness (6). Further studies, particularly on elucidating potential reservoirs and vectors, will result in a better understanding of the epidemiology of this disease in Iran. In the meantime, MSF should be included in the differential diagnosis for patients in Iran who are experiencing fever and rash.

The work presented in this publication was supported by the Pasteur Institute of Iran and the Center for Communicable Diseases Control in the Ministry of Health (grant no. 810).

\section{About the Author}

Dr. Esmaeili is an assistant professor and researcher in medical microbiology at Pasteur Institute of Iran. His primary research interest is emerging and reemerging bacterial pathogens, including Coxiella burnetii, Bartonella, Francisella, Rickettsia, and Yersinia pestis. 

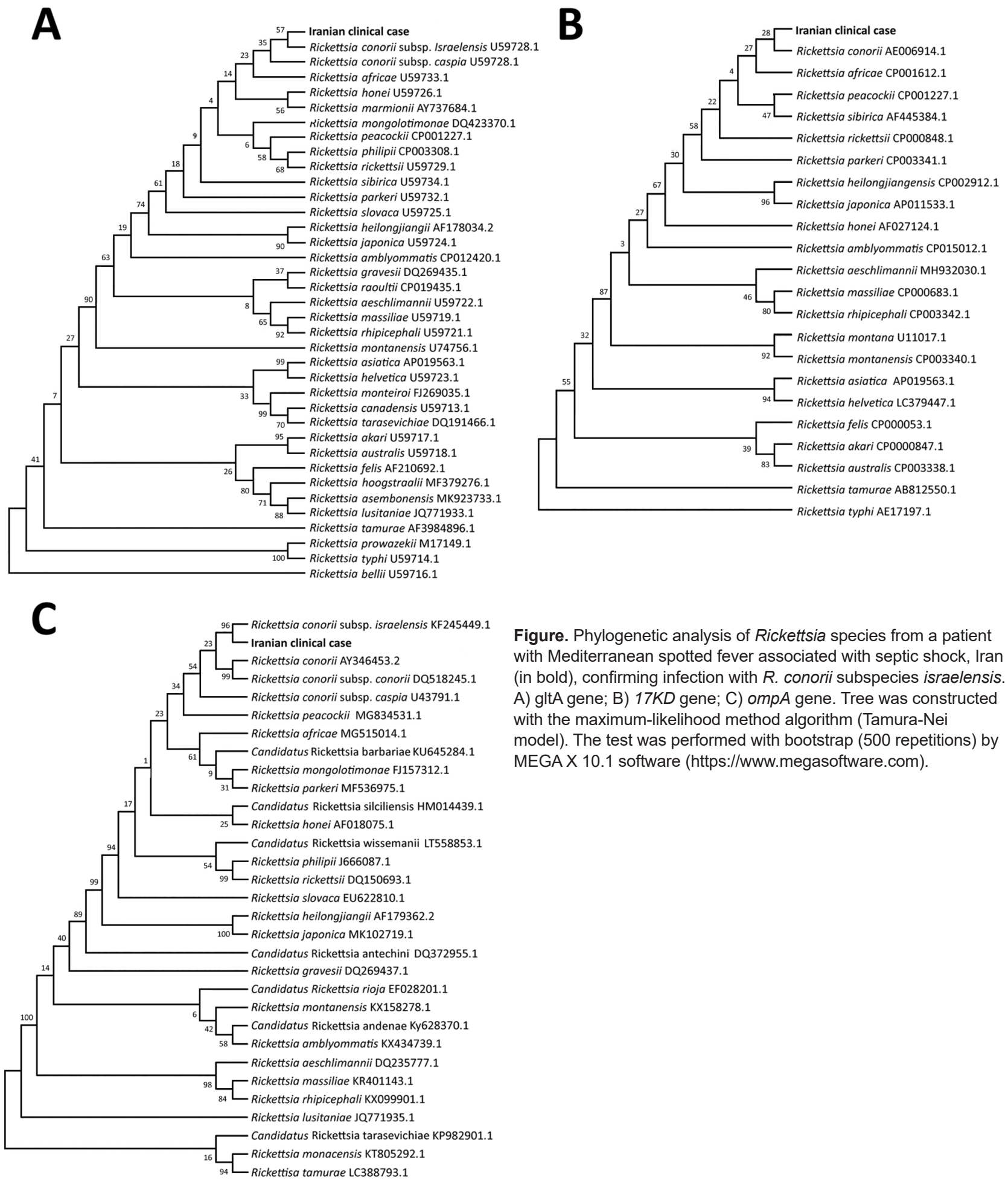

Figure. Phylogenetic analysis of Rickettsia species from a patient with Mediterranean spotted fever associated with septic shock, Iran (in bold), confirming infection with $R$. conorii subspecies israelensis. A) gltA gene; B) $17 K D$ gene; C) ompA gene. Tree was constructed with the maximum-likelihood method algorithm (Tamura-Nei model). The test was performed with bootstrap (500 repetitions) by MEGA X 10.1 software (https://www.megasoftware.com).

\section{References}

1. Rovery C, Brouqui P, Raoult D. Questions on Mediterranean spotted fever a century after its discovery. Emerg Infect Dis. 2008;14:1360-7. https://doi.org/10.3201/eid1409.071133

2. Nafi O, Tarawnah Y, Tarawnah A. Epidemiological evaluation of Mediterranean spotted fever in children of

the Karak province in south Jordan. J Infect Dev Ctries. 2017;11:242-6. https://doi.org/10.3855/jidc.8154

3. Parola P, Paddock CD, Raoult D. Tick-borne rickettsioses around the world: emerging diseases challenging old concepts. Clin Microbiol Rev. 2005;18:719-56. https://doi.org/10.1128/CMR.18.4.719-756.2005 
4. Baymakova M, Pekova L, Plochev K, Parousheva P. Severe clinical forms of Mediterranean spotted fever: a case series from an endemic area in Bulgaria. Int J Infect Dis. 2016;53:150-1. https://doi.org/10.1016/j.ijid.2016.11.369

5. Farrokhnia M, Ghalejoogh ZY, Rohani M, Ghasemi A, Esmaeili S, Mostafavi E. Cases of Mediterranean spotted fever in southeast of Iran. Iran J Microbiol. 2020;12:256-60. https://doi.org/10.18502/ijm.v12i3.3244

6. Abdeljelil M, Sakly H, Kooli I, Marrakchi W, Aouam A, Loussaief C, et al. Mediterranean spotted fever as a cause of septic shock. IDCases. 2019;15:e00528. https://doi.org/ 10.1016/j.idcr.2019.e00528

7. Walker DH, Herrero-Herrero JI, Ruiz-Beltrán R, Bullón-Sopelana A, Ramos-Hidalgo A. The pathology of fatal Mediterranean spotted fever. Am J Clin Pathol. 1987;87:669 72. https:// doi.org/10.1093/ajcp/87.5.669

8. Parola P, Paddock CD, Socolovschi C, Labruna MB, Mediannikov O, Kernif T, et al. Update on tick-borne rickettsioses around the world: a geographic approach. Clin Microbiol Rev. 2013;26:657-702. https://doi.org/10.1128/CMR.00032-13

9. Cohen R, Babushkin F, Shapiro M, Uda M, Atiya-Nasagi Y, Klein D, et al. Two cases of Israeli spotted fever with Purpura fulminans, Sharon District, Israel. Emerg Infect Dis. 2018;24:835-40. https:/ / doi.org/10.3201/eid2405.171992

10. Sousa R, França A, Dória Nòbrega S, Belo A, Amaro M, Abreu T, et al. Host- and microbe-related risk factors for and pathophysiology of fatal Rickettsia conorii infection in Portuguese patients. J Infect Dis. 2008;198:576-85. https://doi.org/10.1086/590211

Address for correspondence:_Saber Esmaeili, No. 69, Pasteur Ave, Department of Epidemiology and Biostatistics, Pasteur Institute of Iran, Postal Code 1316943551, Tehran, Iran; email: dr.saberesmaeili@gmail.com, s-esmaeili@pasteur.ac.ir

\section{Genetic Diversity of Bartonella spp. in Cave- Dwelling Bats and Bat Flies, Costa Rica, 2018}

\author{
Miranda M. Mitchell, ${ }^{1}$ Amanda Vicente-Santos, ${ }^{1}$ \\ Bernal Rodríguez-Herrera, Eugenia Corrales-Aguilar, \\ Thomas R. Gillespie
}

\begin{abstract}
Author affiliations: Emory University, Atlanta, Georgia, USA (M.M. Mitchell, A. Vicente-Santos, T.R. Gillespie); University of Costa Rica, San José, Costa Rica (B. Rodríguez-Herrera, E. Corrales-Aguilar)

DOI: https://doi.org/10.3201/eid2802.211686
\end{abstract}

${ }^{1}$ These authors contributed equally to this article.
To determine Bartonella spp. dynamics, we sampled bats and bat flies across 15 roosts in Costa Rica. PCR indicated prevalence of $10.7 \%$ in bats and $29.0 \%$ in ectoparasite pools. Phylogenetic analysis of 8 sequences from bats and 5 from bat fly pools revealed 11 distinct genetic variants, including 2 potentially new genotypes.

$B$ artonella, the causative agent of bartonellosis, is a genus of gram-negative bacteria. Bartonellosis causes a range of symptoms from severe to life-threatening (e.g., endocarditis and meningitis). Clinical syndromes from Bartonella infections include trench fever (B. quintana), cat scratch disease (B. henselae), and Carrion's disease (B. bacilliformis) (1). Bats (Order Chiroptera) and their blood-

\begin{tabular}{|c|c|}
\hline Species & No. positive/no. sampled \\
\hline \multicolumn{2}{|l|}{ Bats } \\
\hline Artibeus jamaicensis & $0 / 1$ \\
\hline Balantiopteryx plicata & $0 / 4$ \\
\hline Carollia perspicillata & $19 / 79$ \\
\hline Desmodus rotundus & $1 / 25$ \\
\hline Diphylla ecaudata & $0 / 1$ \\
\hline Glossophaga commisarisi & $0 / 12$ \\
\hline Glossophaga soricina & $0 / 10$ \\
\hline Lonchophylla robusta & $1 / 25$ \\
\hline Lonchorhina aurita & $0 / 13$ \\
\hline Macrophyllum macrophyllum & $1 / 1$ \\
\hline Phyllostomus hastatus & $0 / 4$ \\
\hline Pteronotus gymnonotus & $3 / 11$ \\
\hline Pteronotus mesoamericanus & $2 / 56$ \\
\hline Pteropteryx kappleri & $0 / 1$ \\
\hline Tonatia saurophilia & $0 / 1$ \\
\hline Trachops cirrhosis & $0 / 8$ \\
\hline Total & $27 / 252$ \\
\hline \multicolumn{2}{|l|}{ Bat flies } \\
\hline Aspidoptera phyllostomasis & $0 / 1$ \\
\hline Exastinion clovisi & $2 / 2$ \\
\hline Megistopoda aranea & $1 / 4$ \\
\hline Speiseria ambigua & $0 / 1$ \\
\hline Strebla carolliae & $0 / 1$ \\
\hline Strebla diaemi & $0 / 1$ \\
\hline Strebla galindoi† & $1 / 2$ \\
\hline Strebla guajiro & $0 / 1$ \\
\hline Strebla hertigi† & $1 / 1$ \\
\hline Strebla mirabilis & $0 / 1$ \\
\hline Strebla vespertilionis $\dagger$ & $2 / 2$ \\
\hline Trichobius cecus & $0 / 3$ \\
\hline Trichobius dugesiodes & $0 / 2$ \\
\hline Trichobius dunni & $0 / 1$ \\
\hline Trichobius furmani & $0 / 1$ \\
\hline Trichobius galei & $0 / 3$ \\
\hline Trichobius johnsonae & $1 / 3$ \\
\hline Trichobius keenani & $0 / 1$ \\
\hline Trichobius pallidus $\dagger$ & $7 / 22$ \\
\hline Trichobius perspicillata & $0 / 1$ \\
\hline Trichobius sparsus $\dagger$ & $2 / 3$ \\
\hline Trichobius uniformis & $1 / 2$ \\
\hline Trichobius yunkeri & $0 / 3$ \\
\hline Total & $18 / 62$ \\
\hline
\end{tabular}

${ }^{\star}$ For bat flies, no. sampled indicates no. sampled pools. †Newly described species with Bartonella. 